\title{
QUALITY ASSESSMENT OF THE ESSENTIAL OILS FROM NARDOSTACHYS JATAMANSI (D. DON) DC AND NARDOSTACHYS CHINENSIS BATAL OBTAINED FROM KATHMANDU VALLEY MARKET
}

\author{
Mahesh P. Paudyal*, Meena Rajbhandari**, Purushottam Basnet***, Shoji Yahara**** \\ and Mohan B. Gewali* \\ *Central Department of Chemistry, Kirtipur, Kathmandu, Nepal. \\ ***Research Centre for Applied Science and Technology, Tribhuvan University, Kirtipur, Kathmandu, Nepal. \\ ***School of Health and Allied Sciences, Pokhara University, Pokhara, Nepal (at present, Tromso University, Tromso, Norway). \\ *****Faculty of Pharmaceutical Sciences, Kumamoto University, Kumamoto, Japan.
}

\begin{abstract}
The chemical composition and physicochemical parameters of the essential oils obtained from two species of Nardostachys available in Kathmandu market, $N$. jatamansi (D. Don) and N. chinensis Batal were determined. GC-MS technique was used for the analysis of the oils. Both oils were characterized by high content of sesquiterpenes. $\hat{a}$-gurjunene and jatamansone were the major sesquiterpene components of both oils. Somewhat variation in the amount of chemical components was found in two different species. The physical and chemical parameters such as specific gravity, specific rotation, refractive index and saponification value, acid number, iodine number were very similar for both species. Both oils were, therefore, of comparable quality.
\end{abstract}

Key words: Essential oil; Nardostachys; GC-MS; Physiochemical parameters.

\section{INTRODUCTION}

The genus Nardostachys commonly known as Jatamansi is an erect perennial rhizomatous herb of the family Valerianaceae. It consists of two species, $N$. jatamansi and $N$. chinensis widespread throughout the northern part of alpine to sub alpine Himalayan region at an altitude of 3000$5000 \mathrm{~m}$. The rhizome is the source of Spikenard oil. Traditionally, Jatamansi is used as tonic, stimulant and antiseptic and also used for the treatment of epilepsy, hysteria, convolutions, heart palpitation, intestinal colic and antiarrhythmic activities (1) and also is the active components of many Ayurvedic formulations such as Tapaswiniwati, Jestalabangadi, Chandanadi churna and Rachhogna ghrit (2) etc. Both species are commonly available in the local markets of Kathmandu.

Extensive work on the chemical constituents as well as on the composition of the essential oils of Nardostachys is reported in literature (3-9). Several studies investigated the antioxidant, cytoprotective, hepatoprotective, nerve growth promoting, tranquilizing, memory enhancing, fungitoxic and antibacterial activities (10-16)

The economic potential of Jatamansi is very good as it is the second highest exportable herbs of Nepal. In the past, the herbs were exported in the crude state. But nowadays, according the policy of the Nepalese government the oil is exported after processing the herb. Therefore, it is deemed necessary to access the quality of the oils obtained from the Jatamansi available in the local market. In this paper we report the comparative chemical composition and physicochemical properties of the oil obtained from $N$. jatamansi and $N$. chinensis.

\section{MATERIALS AND METHODS}

\section{Plant materials}

The rhizomes of Jatamansi were purchased from two different local vendors, one from Itumbahal, Kathmandu and other from Chapagaon, Lalitpur. They were identified as $N$. jatamansi and $N$. chinensis respectively by Prof. R. P. Chaudhary, Central Department of Botany, Tribhuvan University. The voucher specimens were deposited at the Central Department of Botany.

\section{Volatile oil extraction}

The two species of Jatamansi (100 g each) were hydrodistiled for 4-5 h in a Clevenger type apparatus to yield

Author for Correspondence: Mohan B. Gewali, Central Department of Chemistry, Kirtipur, Kathmandu, Nepal. Email: mbgewali@gmail.com 
two oils. The oils were collected and dried over $\mathrm{Na}_{2} \mathrm{SO}_{4}$ and stored at $4^{\circ} \mathrm{C}$ for further use.

\section{Gas chromatography-mass spectrometry}

Analytical GC was recorded on gas chromatograph with a flame ionization detector using a capillary $30 \mathrm{~m}$ DB-5 column (J and W Scientific, USA) with $0.25 \mathrm{~mm}$ i.d. and 0.1 $\mathrm{mm}$ film thickness. The temperature program was $50^{\circ} \mathrm{C}$ for 2 minute and increased at $10^{\circ} \mathrm{C} /$ minute up to $300^{\circ} \mathrm{C}$ for 3 minute. The carrier gas was Helium at a flow rate $1 \mathrm{ml} / \mathrm{min}$. MS was operated in the electron impact mode with an ionization energy of $70 \mathrm{eV}$ on a JEOL AX505 mass spectrometer connected to HP-9000 computer system.

The detected compounds were identified by processing the raw GC-MS data and comparing with National Institute of Standard and Technology, NIST, USA mass spectral database and from retention times and mass spectra of standard compounds. Relative amounts of detected compounds were calculated based on GC peak areas.

\section{Determination of physical parameters}

Physical parameters were determined according to the method of Guenther (17)

\section{Specific gravity determination}

An ignition tube of known weight (W) was filled first with essential oil and then with water and the respective weight $\mathrm{W}_{1}$ and $\mathrm{W}_{2}$ was determined. Then, the specific gravity was calculated using the formula,

$$
\mathrm{d}_{\mathrm{t}}=\frac{\mathrm{W}_{1}-\mathrm{W}}{\mathrm{W}_{2}-\mathrm{W}}
$$

\section{Refractive index determination}

The refractive index of the oil was measured by using Abbe's refractometer.

\section{Optical Rotation Determination}

Different concentration of oil solutions (1.0\%, 0.5\%, $0.25 \%$ ) were prepared in methanol and the optical rotation was measured for the solutions of different concentrations. Then the specific rotation was calculated using the formula,

$$
[\alpha]_{D}^{\mathrm{t}}=\frac{\mathrm{a}}{1 \times \mathrm{c}}
$$

Where, á is the angle of rotation of the plane of plane polarized Light, $\mathrm{l}$ is the length of polarimeter tube (mm) and $\mathrm{c}$ is the concentration of oil solution

\section{Determination of chemical parameters}

\section{Saponification value determination}

Saponification value was determined by standard procedure. Jatamansi oil (0.5 gm) was accurately weighed and dissolved in $10 \mathrm{ml}$ of ethanol and then $10 \mathrm{ml}$ of 2.5 N potassium hydroxide $(\mathrm{KOH})$ solution was added. This procedure was performed in duplicate and blank experiment was also performed omitting the oil. The mixture was refluxed for two hours then cooled. The unreacted $\mathrm{KOH}$ was titrated with standard N/2 oxalic acid by adding 2-3 drops of phenolphthalein indicator. Then, the saponification value was determined using the following equation.

$$
\text { Saponification value }=\frac{56 \times\left(\mathrm{V}_{1}-\mathrm{V}_{2}\right) \times 1000}{2 \times 1000 \times \mathrm{W}}
$$

Where, $\mathrm{W}$ is the weight of oil, $\mathrm{V}_{1}$ is the volume of $\mathrm{N} / 2$ oxalic acid for blank, $\mathrm{V}_{2}$ is the volume of N/2 oxalic acid for sample

\section{Acid value determination}

Acid value was determined according to the method of Guenther (17). Oil (0.5 gm) was accurately weighted and dissolved in $10 \mathrm{ml}$ of $95 \%$ ethanol and 2-3 drops of phenolphthalein indicator was added. The free acid was then titrated with standard $0.1 \mathrm{~N}$ aqueous sodium hydroxide solution by adding the alkali drop-wise at a uniform rate of about 30 drops per minute. The content of the flask was continuously agitated. The first appearance of the red coloration that did not fade within 10 seconds was considered the end point. Then, the acid value (A.V) was calculated using the following equation,

$$
\text { Acid value }=\frac{5.61(\text { number of } \mathrm{mL} \text { of } 0.1 \mathrm{~N} \mathrm{NaOH})}{\text { Weight of sample in gram }}
$$

\section{Iodine number determination}

Iodine number was determined according to the method of Guenther (17). Oil (0.25 gm) was dissolved in $10 \mathrm{ml}$ of chloroform. Then $25 \mathrm{ml}$ of iodobromide solution was added and allowed to stand for 30 minutes in dark. Again $30 \mathrm{ml}$ of $1 \mathrm{~N}$ potassium iodide and $100 \mathrm{ml}$ of distilled water were added and the liberated iodine was titrated with N/10 solution of sodium thiosulphate with constant shaking. When iodine color became quite pale, $1 \mathrm{ml}$ of $1 \%$ starch solution was added and the titration was continued until the blue color was discharged. A blank test was also carried out parallel under identical condition. The iodine number was determined using the formula,

$$
\text { Iodine number }=\frac{1.269\left(\mathrm{~V}_{1}-\mathrm{V}_{2}\right)}{\mathrm{W}}
$$

Where, $\mathrm{W}$ is the weight of sample, $\mathrm{V}_{1}$ is the number of $\mathrm{ml}$ of thiosulphate consumed by the blank, $\mathrm{V}_{2}$ is the number of $\mathrm{ml}$ of thiosulphate consumed by the test sample.

Iodobromide solution was prepared by dissolving iodine (13.2 gm ) in $1000 \mathrm{ml}$ glacial acetic acid by gentle heating. The solution was cooled to $25^{\circ} \mathrm{C}$ and the iodine content in $20 \mathrm{ml}$ was determined by titration with N/10 Sodium thiosulphate. To the remaining of the solution a quantity of bromine molecularly equivalent to that of the iodine present was added. 
Table 1. Main components of essential oils of $N$. jatamansi and $N$. chinensis

\begin{tabular}{|c|c|c|c|}
\hline No & Compounds & $\begin{array}{c}N . \\
\text { jatamansi }\end{array}$ & $\begin{array}{c}N . \\
\text { chinensis }\end{array}$ \\
\hline 1 & 4-(1,-dimethylethyl)-benzenemethanol & 0.35 & 0.49 \\
\hline 2 & $\alpha$-gurjunene & trace & Trace \\
\hline 3 & $\begin{array}{l}\text { 1a, } 2,3,3 \mathrm{a}, 4,5,6,7 \mathrm{~b} \text {-octahydro-1,1,3a,7-tetramethyl-1H- } \\
\text { cyclopropanaphthelene }\end{array}$ & 5.57 & 1.68 \\
\hline 4 & $\beta$-patchoulene & 3.60 & 1.15 \\
\hline 5 & $\beta$-gurjunene & 29.10 & 14.81 \\
\hline 6 & $\delta$-cadinene & 0.98 & 0.79 \\
\hline 7 & $\gamma$-cadinene & 0.81 & 1.46 \\
\hline 8 & $\begin{array}{l}\text { 1,2,3,4,4a,5,6,7,8,8a-decahydro-1,4a-dimethyl-7-(1- } \\
\text { methylethylidene)-1-naphthalenol }\end{array}$ & 0.89 & Trace \\
\hline 9 & $\begin{array}{l}1,2,3,4,5,6,7,8 \mathrm{a} \text {-octadydro- } 3,6,8,8 \text {-tetramethyl- } 1 \mathrm{H}-3 \mathrm{a} \text {, } \\
\text { methanoazulene }\end{array}$ & 0.93 & 3.13 \\
\hline 10 & Carotol & 1.13 & 2.20 \\
\hline 11 & $a$-cadinol & 0.44 & 1.94 \\
\hline 12 & $\begin{array}{l}\text { 4,4a,5,6,7,8-hexahydro- } 4,4 \mathrm{a} \text {-dimethyl-6-( } 1 \text {-methyl- } \\
\text { ethylidene)- } 2(3 \mathrm{H}) \text {-naphthalenone }\end{array}$ & 0.99 & 4.94 \\
\hline 13 & Jatamansone & 9.71 & 8.01 \\
\hline 14 & 4-methoxy-7H-furo 3, 2-g-1-benzopyran-7-one & 2.43 & 5.91 \\
\hline \multirow[t]{2}{*}{15} & Aristolenone & 6.48 & 6.66 \\
\hline & Total & 63.41 & 53.17 \\
\hline
\end{tabular}

Table 2. Physico-chemical parameters of essential oils

\begin{tabular}{lrr}
\hline \multicolumn{1}{c}{ Parameters } & N.jatamansi & N. chinensis \\
\hline Specific gravity & 0.9529 & 0.9586 \\
Refractive index & 1.476 & 1.496 \\
Specific rotation & $-37.5^{\circ}$ & $-42.5^{\circ}$ \\
Saponification value & 84.0 & 72.8 \\
Acid value & 48.1 & 45.2 \\
lodine value & 149.57 & 153.60 \\
\hline
\end{tabular}

\section{RESULTS AND DISCUSSION}

The essential oils obtained by hydrodistillation of the rhizomes of $N$. jatamansi and $N$. chinensis were slightly viscous oil with strong spicy order. They differ slightly in color with light green for $N$. jatamansi and yellowish green for $N$. chinensis. The yields were $1.5 \%$ for N. jatamansi and $1.7 \%$ for $N$. chinensis on dry weight basis.

The GC analysis of essential oils of $N$. jatamansi and $N$. chinensis allowed the detection of 31 and 32 components respectively and 15 components were identified on both species on the basis of retention time and comparing with mass spectral database of standard compounds. They accounted for $63.41 \%$ and $53.17 \%$ of the two essential oils of $N$. jatamansi and $N$. chinensis respectively.

Out of 15 components, 13 in both oils were identified as sesquiterpenes, one as aromatic compound and one as coumarin derivative. The major sesquiterpene constituents identified in both $N$. jatamansi and $N$. chinensis were $\hat{a}-$ gurjunene and jatamansone with some variation in their amount (Table 1).

Monoterpenes such as á-pinene, camphene, limonene, 1, 8-cineole and sesquiterpenes such as jatamanson, nardostachone, á-gurjunene, $\hat{a}$ - gurjunene, aristolenone, ápatchoulene, $\hat{a}$ - patchoulene, patchoulialcohol, nardol, $\hat{a}-$ maaliene, eudesmane jatamols, spirojatamol (3, 4, 6,18, 19) have been reported in $N$. jatamansi. Similarly, sesquiterpenes such as aristolene, $\hat{a}$-maaliene, isonardosione, nardostachin, nardofuran, nardoquaianone (3, 20-22) have been reported in $N$. chinensis.

However, comparison of our results with the literature indicated that in both species, monoterpenes were not identified, several previously unreported sesquiterpenes were identified and the aromatic compound and the coumarin derivative were reported for the first time. However, the main components (which were identified) of the chemical composition of the two locally available Jatamansi essential oils looked very similar and somewhat different from that reported in the literature. Therefore, it became necessary to identify all the unidentified GC peaks by comparison with mass spectral database which would provide the complete picture of chemical components present in the oil.

The physicochemical properties of the oils were evaluated using the standard procedure and the results are presented in Table 2. The specific gravity and refractive index values are close to each other. Both oils are levorotatory. The saponification value and acid number is slightly greater for $N$. jatamansi indicated the presence of high amount of fatty acids and free acids where but iodine value is slightly greater for $N$. chinensis indicated the presence of more unsaturated compounds.

In conclusion, based on the chemical profile and physicochemical parameters the two essential oils obtained from $N$. jatamansi and $N$. chinensis obtained from Kathmandu valley market were found to be of comparable quality. The minor differences might have arisen due to the difference in climatic and topographic condition of habitat and harvesting as well as duration and the condition of storage of the samples (23).

\section{ACKNOWLEDGEMENT}

This study was accomplished from a grant from Volkswagen Foundation, Germany.

\section{References}

1. Anonymous. 1985. Wealth of India. A Dictionary of Indian Raw materials and Industrial Products. The Publication and Information Directorate, New Delhi, VII:3-4.

2. Adhakari, S. 1998. Health care by Local Resources. Mahendra Sanskrit Vishwa Vidyalaya. 48-49.

3. Sun, H. D., Ding, J. K., Lin, Z. W., Che, F. R., , 1980. Acta Botany Yunnanica 2(2): 213-223.

4. Bagchi, A., Oshima, Y., Hikino, H., 1990. Tetrahedron 46 (5), 1523-1530.

5. Bagchi, A., Oshima, Y., Hikino, H., 1991. Planta Medica 57(3), 282-283.

6. Bagchi, A., Oshima, Y., Hikino, H., 1991. Planta Medica 57 (1), 96-97.

7. Kawashima, A., Kishimoto, M., Morimoto, S., Akayama, T., Maejima, A., Kawada, I. 1996. Applied Chemistry 13, 478481.

8. Chaterjee, A., Basak, B., Saha, M., Weulta, U., Mukhopadhaya, C., Benargi, J., Konda, Y., Harigaya, Y. 2002. Journal of Natural Products. 63 (11) 1531-1533.

9. Tanaka, K. K., Katsuko. 2008. Journal of Natural Medicine. 148 (62), 112-116. 
10. Salim, S., Ahamad, M., Zafar, K. S., Ahamad, A. S., Islam S. 2003. Pharmacology, Biochemistry and Behavior 74 (2), 481486.

11. Joshi, H., Parle, M. 2006. Journal of Medicinal Food. 9 (1), 113-118.

12. Ali, S., Ansari, K. A., Jafry, M. A., Kabeer, H., Diwakar, G. 2000. Journal of Ethnopharmacology. 71-359-363.

13. Matsunaga, K., Yamamoto, K., Yosikawa, R., Kawasima, K., Ohizumi, Y. 1999. Neuroscience letter 273, 53-56.

14. Sarbhoy, A. K., Varshney, j. L., aheshwori, M. L., Saxene, D. B. 1978. Zentralblatt Baketeriol Naturewissnsshaft 133 (7-8), 723-725.

15. Mishra, D. Chaturvedi, R. V., Tripathi, S. C. 1995. Tropical Agriculture 72, 48-52.

16. Timisina, G. 2003. M. Sc. Dessertation, Central Department of Botany. Tribhuvan University.

17. Guenther, E., 1960. The Essential oils. D-van Nostrand
Company, Princeton, New Jersey, New York, I, 237-306.

18. Bruns, K., Das Etherusche ole aus Nardostachys jatamansi. 1980. 11th International Arbeitstagung, Vorkomen Analytic Etherische ole, Groningen, Neatherland.

19. Sastry, S. D., Maheshwari, K. L, Chakravarti, K. K., Battacharya, S. C. Terpenoids of Nardostachys jatamansi. 1967. Perfume: Essential oil Research 84, 154-158.

20. Shide, L., Reucker, G., Olbrich, A., Mayer, R. 1987. Planta Medica 53 (6), 556-558.

21. Bhagchi, A., Oshima, Y., Hikino, H. 1988. Planta Medica. 54 (1), 87-88.

22. Tanitsu, M., Takaya, Y., Akasaka, M., Niwa, M., Oshima, Y. 2002. Phytochemistry 59 (8), 845-849.

23. Alexandrov, A. V., Zinchenko, A. A. 2003. Essential oil quality and standards, with special reference to Mentha oil. Ukraine. 